\title{
Long term indwelling urethral catheterisation for congenital neuropathic bladder
}

\author{
A M K RICKWOOD, N H PHILP, AND D G THOMAS \\ Spinal Injuries Unit, Lodge Moor Hospital, and Sub Department of Paediatric Surgery, Children's Hospital \\ Sheffield
}

SUMMARY Long term urethral catheterisation remains an important and effective method of achieveing dryness and maintaining renal function in children with congenital neuropathic bladders. Those most likely to require an indwelling catheter are girls who are severely disabled because of myelomeningocele. The management of such catheterisation and its consequences, in the light of our experience with a 100 children treated over a 12 year period, is described.

Until recently permanent urinary diversion was commonly performed in patients with congenital neuropathic bladder. There is now ample evidence that the long term results of such procedures performed in children are poor ${ }^{1-3}$ and this has prompted a search for alternative forms of management. More than a decade ago we began to use indwelling urethral catheters, at first as a temporising measure in those unfit for surgery and later as a definitive treatment. Since then other methods have become established-notably, clean intermittent self catheterisation, ${ }^{4}$ various forms of medication, ${ }^{5}$ and prosthetic urinary sphincters ${ }^{6}$-but we still consider indwelling urethral catheterisation to be the most appropriate treatment for selected cases.

Our experience with this method includes 100 children treated from 1969 to 1981 , of whom most were girls (90) and cases of myelomeningocele (95). Age at the beginning of catheterisation ranged from 15 months to 15 years.

\section{Selection of patients for indwelling catheterisation}

Management of the congenital neuropathic bladder has two objectives, maintenance of renal function and dryness. Deteriorating renal function is almost always secondary to bladder outlet obstruction, which must therefore be eliminated or bypassed. Dryness is ideally achieved without recourse to a urinary appliance and in a manner the older child can practise independently. Appliance free continence demands a bladder of adequate functional capacity, but the definition of 'adequate' is largely determined by mobility. For a patient confined to a wheelchair, a bladder capacity which ensures dryness for at least 4 hours is required. Functional capacity may be reduced by unstable (reflex) detrusor contractions, reduced detrusor compliance, sphincter weakness, or any combination of these. The first two often improve with an anticholinergic drug or drugs with a direct inhibitory effect on the detrusor, and clean intermittent self catheterisation is often used with such agents. Sphincter weakness is less responsive to medication and often the only effective treatment for this condition is the prosthetic urinary sphincter. Unfortunately, consideration of cost alone rules out this device for all but a few selected patients.

Even if functional bladder capacity is adequate, or can be rendered so with suitable drugs, many spina bifida patients cannot practise clean intermittent self catheterisation independently, the main limiting factors being low intelligence and poor hand-eye coordination associated with hydrocephalus, ${ }^{7}$ major spinal deformities in girls, and good urethral sensation in boys with incomplete cord lesions.

For boys with bladder outlet obstruction, who cannot become appliance free independently, there is usually the alternative of a penile urinal plus endoscopic sphincterotomy. There may be complications with long term catheterisation of the male urethra, and we reserve it for a few adolescents with a penis too small to be fitted with an appliance and the occasional child with severe upper renal tract 
deterioration that is unlikely to respond to sphincterotomy.

For girls who cannot become independently appliance free, the only alternative to urinary diversion or continued incontinence is an indwelling catheter.

In summary, catheterisation in girls is indicated for the more severely disabled, almost regardless of their bladder dysfunction, and for some of the less disabled because they lack adequate functional capacity due to sphincter weakness. The factors which incline us toward indwelling catheterisation are summarised in Table 1 and it will be noted that in our own experience most of the patients are more severely physically or intellectually disabled.

\section{Basics of catheterisation}

Because most of our patients attend special schools which are now adept at handling catheters, we usually begin treatment in the outpatient department or at the school. We admit for a few days those attending normal schools so that they and their parents may become familiar with catheters and their problems. Catheter changes are initially undertaken by school or district nurses but we later encourage parents to learn the technique so that the family is less dependent on paramedical staff. A few older girls change their own catheters.

The calibre of the catheter is determined by the patient's size, but it should never exceed 18 FG even for the fully grown. Except in those children with a flaccid bladder and a grossly incompetent bladder neck, balloon size should not exceed $10 \mathrm{ml}$, and is usually restricted to $5 \mathrm{ml}$. There are now several types of self retaining balloon catheters available (Table 2) and the choice is governed mainly by cost. Pure silicone and silicone coated catheters are justified only if they function consistently for at least four weeks. We do not believe that the pure silicone catheters are any better than the cheaper silicone coated types.

Table 1 Factors predisposing to management by indwelling catheter

\begin{tabular}{ll}
\hline Female \\
Neurological lesion above D12 \\
Major spinal deformity \\
IQ below 80 \\
Wheelchair bound \\
Hip adduction deformity \\
Sphincter weakness incontinence \\
$\begin{array}{l}\text { Authors' series }(n=100) \\
\text { Wheelchair bound }\end{array}$ \\
Major spinal deformity & 70 \\
IQ below 80 & 44 \\
Combination of 2 of the above & 41 \\
Combination 3 of the above & 36 \\
\end{tabular}

Table 2 Principal types of self-retaining balloon catheters

\begin{tabular}{lc}
\hline Type & Price range (£) \\
\hline Latex rubber & $\cdot 72$ \\
Silicone coated & $2 \cdot 00-3 \cdot 68$ \\
Pure silicone & $5 \cdot 99-8 \cdot 25$ \\
\hline
\end{tabular}

All 3 types are available from 8-18 FG, with 3-5 ml balloon size.

Catheters must be changed regularly, and not only when they block or give trouble. Latex catheters are changed at intervals not exceeding two weeks and silicone or silicone coated catheters at intervals not exceeding six weeks. Although manufacturers state that they may be left longer, this practice invites the formation of stones and debris in the bladder.

Patients in wheelchairs have the catheter on free drainage into a leg bag. More active children may spiggot the catheter for periods of up to 3 hours.

\section{Complications of long term catheter drainage}

Urinary infection. Urinary infection, or rather bacteriuria, is almost inevitable in patients on long term catheter drainage ${ }^{89}$ but there is little evidence that this is harmful to the kidneys or the bladder. Most episodes are symptomless: 21 of our patients have had symptomatic bacteriuria but only 10 have had recurrent episodes. Symptomatic infections are most common in the first weeks of catheterisation and we give a prophylactic antibiotic for the first month. Urine specimens are taken regularlymonthly for children at special schools-but this is probably unnecessary as we now tend to treat only symptomatic infections.

Haematuria. This is usually an early complication and can be expected to resolve spontaneously.

Catheter blockage. This is the major problem with long term catheter drainage, and occurred in half our patients including 18 who had recurrent episodes. The complication takes two forms. In the first the obstruction is on and in the catheter due to accretion of phosphates, while in the second there is deposition of stones and phosphate debris in the bladder also. The latter has occurred in 6 of our patients, all of whom are postpubertal.

Why some patients are susceptible to catheter blockage is unknown, although infection with urea splitting organisms seems to be a factor. The occasional episode is no more than a minor nuisance, but repeated blockage is a major problem calling for active measures which may include the following, used singly or in combination: (1) A high fluid intake. (2) More frequent catheter changes-if a 
silicone or silicone coated catheter blocks regularly in less than 4 weeks, a latex type is substituted and changed every 1 to 2 weeks. (3) Bladder washouts using tap water (preboiled), aqueous chlorhexidine, noxytiolin, or Renacidin, the last being theoretically the most likely to be effective. The frequency of washouts depends on the scale of the problem and the response obtained, and varies from daily to weekly. (4) Long term administration of a mild urinary antiseptic, such as hexamine hippurate, is often beneficial. (5) Especially in adolescents, repeated episodes of catheter blockage call for cystoscopy and endoscopic removal of any stones or debris.

Catheter bypassing and extrusion. Bypassing, where urine passes around as well as through the catheter, is often mistaken for blockage and treated inappropriately. Both bypassing and extrusion of the catheter with the balloon inflated have a common origin, namely, detrusor spasm, which is stimulated by the presence of the catheter and sometimes exacerbated by a lower urinary tract infection. These complications are therefore limited to patients with reflex detrusor activity and can be anticipated when there is a positive anocutaneous reflex.

It is wrong to try to overcome these problems by increasing the balloon size since this only increases the detrusor spasm. Correct management consists of minimising balloon size (usually to $5 \mathrm{ml}$ ) and long term administration of a detrusor antispasmodic, of which propantheline is the best available. More effective is oxybutynin, which will probably become available in the UK shortly.

Urethral complications. These we have seen in boys only, two developing erosion of the ventral anterior urethra to give a hypospadias-like deformity and one an anterior urethral diverticulum. Urethral complications can occur in girls if drainage problems are treated by ever increasing the calibre of the catheter-a policy which leads to a wide, patulous, and unmanageable urethra. Certainly it is proper to review regularly the calibre of the catheter as the child grows, but, we emphasise that this should never exceed 18 FG.

\section{Results of long term catheterisation}

At the present time 71 of our patients use an indwelling catheter. Fifty three experience virtually no problems, 13 have occasional complications, while 5 have frequent difficulties but prefer a catheter to other forms of treatment. Eleven patients had satisfactory catheter drainage for a year or more, but later changed to other management either electively or as a result of complications; 6 of these are now established on clean intermittent self catheterisation. In 18 cases catheterisation was abandoned in less than a year because of various complications of which blockage was the most common. Most of these early failures occurred some years ago and with our present knowledge it is probable they would now be handled more successfully with a catheter.

Bladder function. There is a belief that long term catheterisation may result in irreversible loss of bladder capacity. Our experience has been that if useful function exists before catheterisation it is retained and that long term catheterisation does not preclude clean intermittent self catheterisation later if this is feasible.

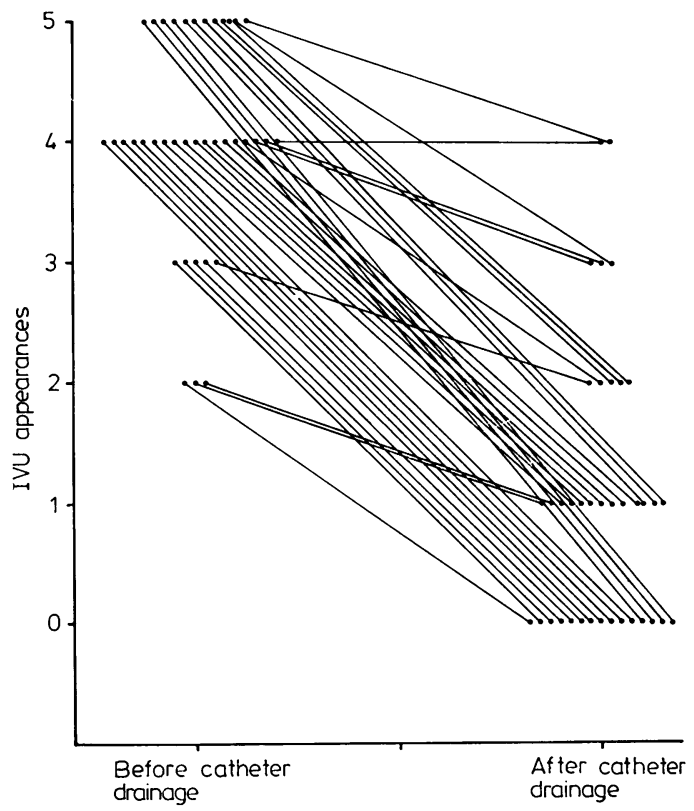

IVU appearances - Grade 0 Normal upper tract

Grade 1 Ureteric distensibility only

Grade 2 Ureteric + pelvicaliceal dilatationmild

Grade 3 Ureteric + pelvicaliceal dilatationmoderate

Grade 4 Ureteric + pelvicaliceal dilatationsevere

Grade 5 Non-function

Fig. 1 Effects of catheterisation on intravenous urogram $(I V U)$ appearances of individual renal units in patients with unilateral or bilateral upper renal tract complications (23 patients, 38 renal units). 
Upper renal tracts. Of our patients managed with a catheter for a year or more, 56 were treated purely for incontinence and had normal upper renal tracts. Only 3 have subsequently shown any deterioration of the intravenous urogram (IVU) appearances after periods of catheter drainage which range from 1 to 13 years.

Progress of 23 patients who had established hydronephrosis ( 38 renal units) before catheterisation is shown in Fig. 1. Follow up in these cases ranged from 1 to 10 years and averaged $4 \cdot 1$ years. Included in this group are 12 patients (14 renal units) with grade II or III vesicoureteric reflux and they have fared as well as those without reflux even though cystography has shown that reflux may remain unchanged after several years of catheterisation (Fig. 2). So far in only one patient has the improvement not been maintained : this girl presented in renal failure, improved considerably for 6 years after catheterisation, and then suddenly died from renal failure.

Three patients were catheterised after urinary undiversion. In two of these the intravenous urogram

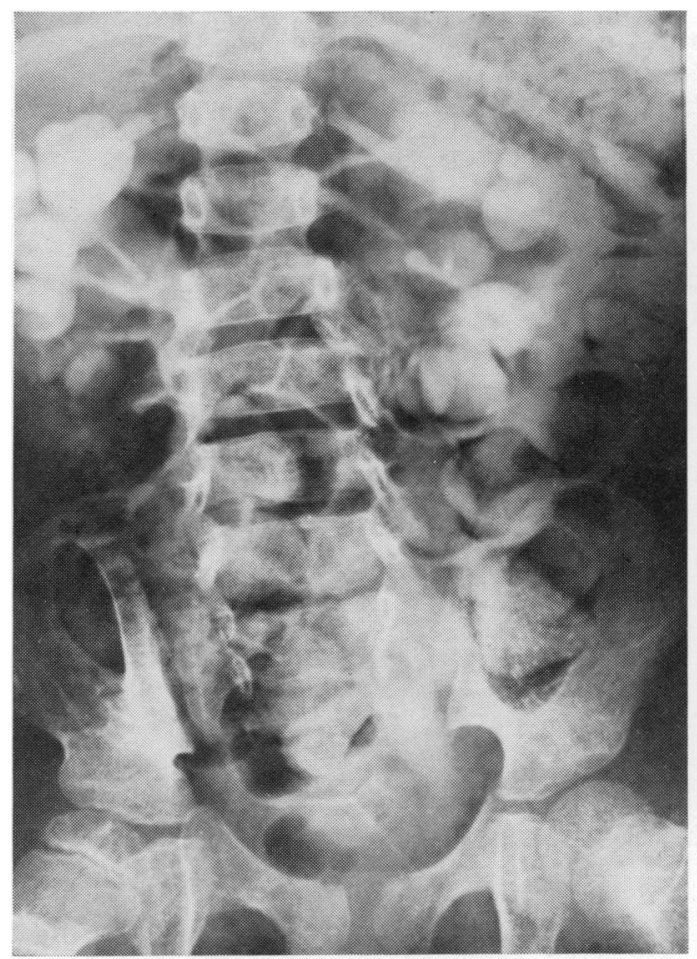

appearances have deteriorated, but this is thought to be entirely due to the surgical procedure.

In terms of preservation of renal function our results with indwelling catheters compare favourably with those of urinary diversion and appear to be at least as good as those obtained by any other method of dealing with bladder outlet obstruction. This, despite the many episodes of bacteriuria, supports the contention that the prime cause of renal deterioration in patients with congenital neuropathic bladder is outlet obstruction rather than urinary infection. Because of the satisfactory results, we monitor the upper renal tracts in these patients less frequently than previously when it was our practice to repeat intravenous urograms at one to two year intervals. As with other units, we are turning to ultrasound and isotope renography to monitor upper tract anatomy and function, and now reckon to do this at three to five year intervals unless there is some specific indication for more frequent study.

\section{Bowel management}

There is little point in keeping patients dry with

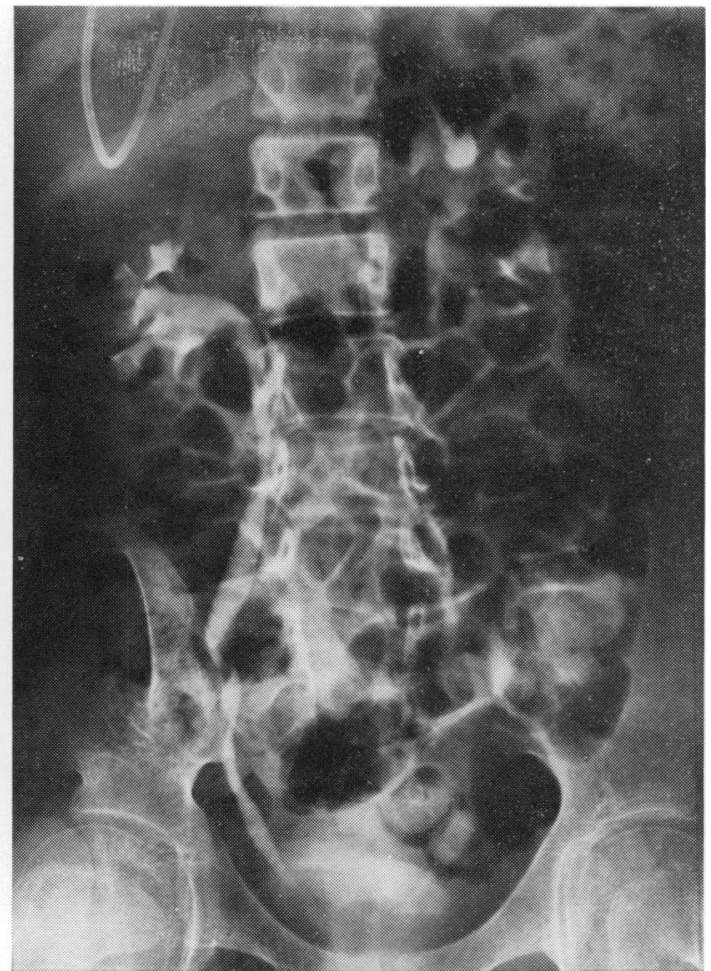

Fig. 2 Left: Girl aged 3 years, thoracolumbar myelomeningocele. IVU showing bilateral hydronephrosis, right grade 3 , left grade 4, associated with bilateral grade III vesicoureteric reflux. Right: Same patient; IVU after 6 years of catherisation showing resolution of the hydronephrosis. A cystogram has shown the reflux to be unchanged. 
catheters if they remain dirty with their bowels. What little has been written on this topic is somewhat opaque. Our policy is simple and generally effective. If the anocutaneous reflex is positive, a bisacodyl suppository or rectal solution is administered, usually on alternate days. This should give a good bowel action within 30 minutes, and no more until the next administration. If the reflex is negative and the motor neurological level is above D12 a manual evacuation is performed, usually daily. If the motor level is below D12 the patient has to strain to defecate daily, but may also need to do a manual evacuation if this manoeuvre does not completely empty the rectum. Bran, senna, etc may be helpful in some cases but are secondary to the basic scheme of treatment.

\section{Envoi}

Use of indwelling urethral catheters has received remarkably little attention in published reports ${ }^{1011}$ and there undoubtedly remains a general distaste for this method of management which stems partly from the practical problems it engenders and partly from an exaggerated view of the importance of bacteriuria in these patients. It is hoped that this article will help answer these objections.

Certainly the proportion of our patients requiring catheterisation has declined with the advent of more modern methods of treatment and will decline still further as a result of a selective policy of treating myelomeningocele. Nevertheless, it is an effective method of achieving dryness and maintaining renal function, and for the more severely disabled girls it is likely to remain the most realistic form of management.

\section{References}

1 Middleton A W, Jr, Hendren W $\mathbf{H}$. Ileal conduits in children at the Massachusetts General Hospital from 1955 to 1970 . J Urol 1976; 115: 591-5.

2 Elder D D, Moisey C U, Rees R W M. A long-term follow-up of the colonic conduit operation in children. Br J Urol 1979; 51 : 462-5.

3 Rickwood A M K. Urinary diversion in children. In: Ashken M H, ed. Urinary diversion. Berlin: Springer, 1982: 22-58.

4 Eckstein H B, Molyneux A. Intermittent catheterisation of the bladder for urinary incontinence. $Z$ Kinderchir 1982; 37: 143-4.

5 Barrett D M, Furlow W L. Management of severe urinary incontinence in patients with myelodysplasia by implantation of AS 791/792 urinary sphincter device. J Urol $1982 ; 128$ : 484-6.

- Rickwood A M K, Thomas D G, Philp N H, Spicer R D. A system of management of the congenital neuropathic bladder based upon combined urodynamic and radiological assessment. Br J Urol 1982; 54: 507-11.

7 Lonton A P. Location of the myelomeningocele and its relationship to subsequent physical and intellectual abilities in children with myelomeningocele associated with hydrocephalus. $Z$ Kinderchir 1977; 22: 51-7.

8 Kass E H. Bacteriuria and the diagnosis of infections in the urinary tract. Arch Intern Med 1957; 100: 709-14.

9 McCleod J W, Mason J M, Neill R W K. Survey of the different urinary infections which develop in the paraplegic and their relative significance. Paraplegia $1965 ; 3: 124-43$.

10 Forrest D M, Tabara $Z$. The indwelling catheter-a reappraisal. $Z$ Kinderchir $1980 ; 31$ : 397-402.

11 Minns R A, Oag J C, Duffy S W, Brown J K, Stark G, McClement E. Indwelling urinary catheters in childhood spinal palsy. $Z$ Kinderchir $1980 ; 31$ : 387-97.

Correspondence to A M K Rickwood FRCS, Spinal Injuries Unit, Lodge Moor Hospital, Sheffield S10 4LH.

Received 10 January 1983 